\title{
Growth, survival and development of house crickets (Acheta domesticus)
}

\section{fed flowering plants}

\author{
M. $\operatorname{Vaga}^{1^{*}}, \AA^{\text {A. Berggren }}{ }^{2}$ and A. Jansson ${ }^{1}$ \\ ${ }^{1}$ Department of Anatomy, Physiology and Biochemistry, P.O. Box 7011, Swedish University of Agricultural Sciences, 75007 \\ Uppsala, Sweden; ${ }^{2}$ Department of Ecology, P.O. Box 7044, Swedish University of Agricultural Sciences, 75007 Uppsala, \\ Sweden; merko.vaga@slu.se
}

Received: 30 May 2020 / Accepted: 22 July 2020

(c) 2020 Wageningen Academic Publishers

OPEN ACCESS C(i) ()(2) RESEARCH ARTICLE

\begin{abstract}
House crickets (Acheta domesticus) are increasingly being used as food. This has the potential for a more efficient food production that also may benefit agroecosystems. As the first study to compare feeds based on European wild flowering plants as feed for house crickets we examined five common plants known to support biodiversity of wild insects (white clover (Trifolium repens), white nettle (Lamium album), common nettle (Urtica dioica), rough comfrey (Symphytum asperum) and common gypsophila (Gypsophila paniculata). These plants and a control diet were fed as dried and sole feeds ad libitum to one-day-old house crickets for 62 days in a climate-controlled laboratory. Cricket weight, mortality and feed intake were recorded every 7 days. An additional test examined crickets preferences for forages and the effect on maturation and weight, by providing a free choice of rapeseed and wheat meal and either an early- or late-cut red clover (Trifolium pratense) or white nettle for 62 days. Mortality of crickets fed common nettle, rough comfrey and common gypsophila exceeded $80 \%$ in first 7 days, so these plants were removed from the trial after 14 days. Survival of crickets on white nettle and control feed was $59 \%$ after 28 days and average cricket weight was similar. By day 62, the weight of crickets fed white nettle and white clover was on average $32 \mathrm{mg}$, compared with $201 \mathrm{mg}$ on control feed. In the free choice test, crickets consumed 15-30\% red clover, 31-37\% wheat meal and $39-64 \%$ rapeseed. Crickets with access to red clover showed a higher $(P<0.001)$ proportion of adults $(28 \%)$ compared with the control (5\%). We conclude that white nettle has potential as feed for house crickets during the early growth stages, and that red clover supplementation increase cricket maturation. Using feeds including white nettle and red clover in cricket rearing additionally benefits to support wild biodiversity and lower feed costs.
\end{abstract}

Keywords: insects, entomophagy, rearing, forages

\section{Introduction}

The environmental impact, production efficiency and sustainability of animal production depends largely on the feed used. Low feed conversion to body mass ratio (FCR) in salmon, poultry and pigs (FCR 1.3, 1.8 and 3.0, respectively) is generally achieved by using some inputs of human-edible feeds (Smil, 2002; Tacon and Metian, 2008; Wilkinson, 2011). However, there are numerous studies on the use of by-products and waste products in the diet of different livestock (Karlsson et al., 2018; Rivin et al., 2012), and the insects as food and feed industry must meet the same future targets to be sustainable. Crickets as feed and food have the potential to utilise low-value, forage-based feeds (Collavo et al., 2005; Miech et al., 2016; Tyree et al., 1976) while maintaining comparatively good growth rate. Miech et al. (2016) found that field crickets (Teleogryllus testaceus) reared in captivity and fed agricultural by-products (cassava tops, Manihot esculenta) and a weed purple cleome (Cleome rutidosperma) had similar growth and FCR as crickets reared on poultry feed. A study by Tyree et al. (1976) found that survival rate and growth performance of house crickets (Acheta domesticus) fed a lucerne and/or timothy diet with $10 \%$ inclusion of synthetic concentrate were as good as in the control (dog food). 
If it were possible to use weeds and flowering plants to produce high-quality animal protein from house crickets, this could also have a positive effect on wild biodiversity (Miech et al., 2016). Increased production of flowering plants in agricultural landscapes would likely benefit biodiversity, by providing feed for bees and other pollinators (Bommarco et al., 2012). We have previously shown that house crickets can utilise red clover (Trifolium pratense) in late bloom with similar efficiency as in early bloom, indicating that red clover can be part of the house cricket diet (Vaga et al., 2020). Identifying efficient, locally produced feed sources is important for establishing environmentally sustainable and cost-efficient production systems (Berggren et al., 2019).

White clover (Trifolium repens) is an established grazing and forage plant in Europe with high flower density (up to 700 flowers $/ \mathrm{m}^{2}$ ) and long flowering time, which is important for honeybee production (Becher et al., 2016; Reyneri et al., 1996). White nettle (Lamium album) and rough comfrey (Symphytum asperum) produce nectar-rich flowers and generally grow on roadsides and field/forest boundary areas in Europe (Mossberg et al., 1992; Sulborska et al., 2014). Both plant species, and also common nettle (Urtica dioica), have long been collected or cultivated for folk medicine and used as food during times of food shortages (tuczaj et al., 2012; Turner et al., 2011). Common nettle is a widely available, cosmopolitan plant with high protein content and is well known for harbouring a diversity of phytophagous and predaceous insects, benefiting biological control and biodiversity (James et al., 2015; Pullin, 1987). Common gypsophila (Gypsophila paniculata) is a garden ornamental plant that can grow well on low fertile sandy soils and is an attractive species for pollinators and arthropods (Darwent and Coupland, 1966; Emery and Doran, 2013).

Inclusions of forages in the diet of house crickets may also have economic benefits, since some studies have shown that mixed forage-based diets outperform expensive concentrate-only feeds (Collavo et al., 2005; Tyree et al., 1976). Based on the limited information available on the feed requirements of house crickets, it is currently not possible to explain the low performance of house crickets on single-forage diets (Cortes Ortiz et al., 2016). However, protein and readily available carbohydrates are suggested to be highly important for maximal growth in house crickets (El-Damanhouri, 2011; Neville and Luckey, 1962; Straub et al., 2019). It is also important that forage inclusion in a mixed diet does not reduce feed intake and that crickets continue to ingest forages even when more protein- and carbohydrate-rich feed sources are available.

In this study, two separate experiments were performed to evaluate: (1) house cricket survival and growth performance on forage-only diets using five European flowering plants; and (2) feed preference, body weight and development in house crickets offered ad libitum access to several feeds, including European flowering plants.

\section{Materials and methods}

\section{Crickets and control feed}

The house crickets used in the study were of wild origin (Uppsala, Sweden) but reared in the laboratory for 4-6 generations. The individuals were reared under controlled conditions with a 12 hours lighting regime, temperature $29 \pm 1^{\circ} \mathrm{C}$ and relative humidity $50 \pm 10 \%$, according to optimal recommended conditions for house crickets (Booth and Kiddell, 2007; Ghouri and McFarlane, 1958). The crickets were known to be free of house cricket densovirus (Semberg et al., 2019). Prior to the study, all individuals were reared on a cereal- and rapeseed-based control feed (as in Vaga et al., 2020), prepared from commercial wheat flour, oat bran, wheat bran, rapeseed meal (ExPro 00SF, AAK AB, Malmö, Sweden), $\mathrm{CaCO}_{3}$ and vitamin-mineral premix (Table 1), and cold-pressed into $\varnothing 3 \mathrm{~mm}$ pellets. In the experiments, nymphs were randomly allocated to control and experimental groups within 24 hours of hatching.

\section{Design and management of experiment 1}

The feeds used in experiment 1 consisted of the control feed and forage-only diets based on five common European flowering plants: white clover, white nettle, rough comfrey, common nettle and common gypsophila (Figure 1). As the feeding study was conducted during winter months, all plants were preserved or acquired as dried material. White clover, white nettle and rough comfrey were collected from the fields around Uppsala during the flowering season in July 2018, when the plants were in full bloom. After harvest, the plants were dried separately in paper bags at room temperature for six days, and then stored in climate stable storage room. Flowering common gypsophila was acquired from a local flower retailer and dried by the same procedure as the other plants. The common nettle product

\section{Table 1. Ingredients of the control feed}

$\begin{array}{lc}\text { Item } & \text { g/kg dry matter } \\ \text { Wheat bran } & 308 \\ \text { Oat bran } & 296 \\ \text { Wheat meal } & 224 \\ {\text { Rapeseed } \text { meal }^{1}}_{\mathrm{CaCO}_{3}} & 150 \\ \text { Premix }^{2} & 17.9 \\ & 4.0\end{array}$

${ }^{1}$ ExPro 00SF (AAK AB, Malmö, Sweden).

${ }^{2}$ Trace elements + vitamin premix (Lantmännen Lantbruk, Malmö, Sweden). 


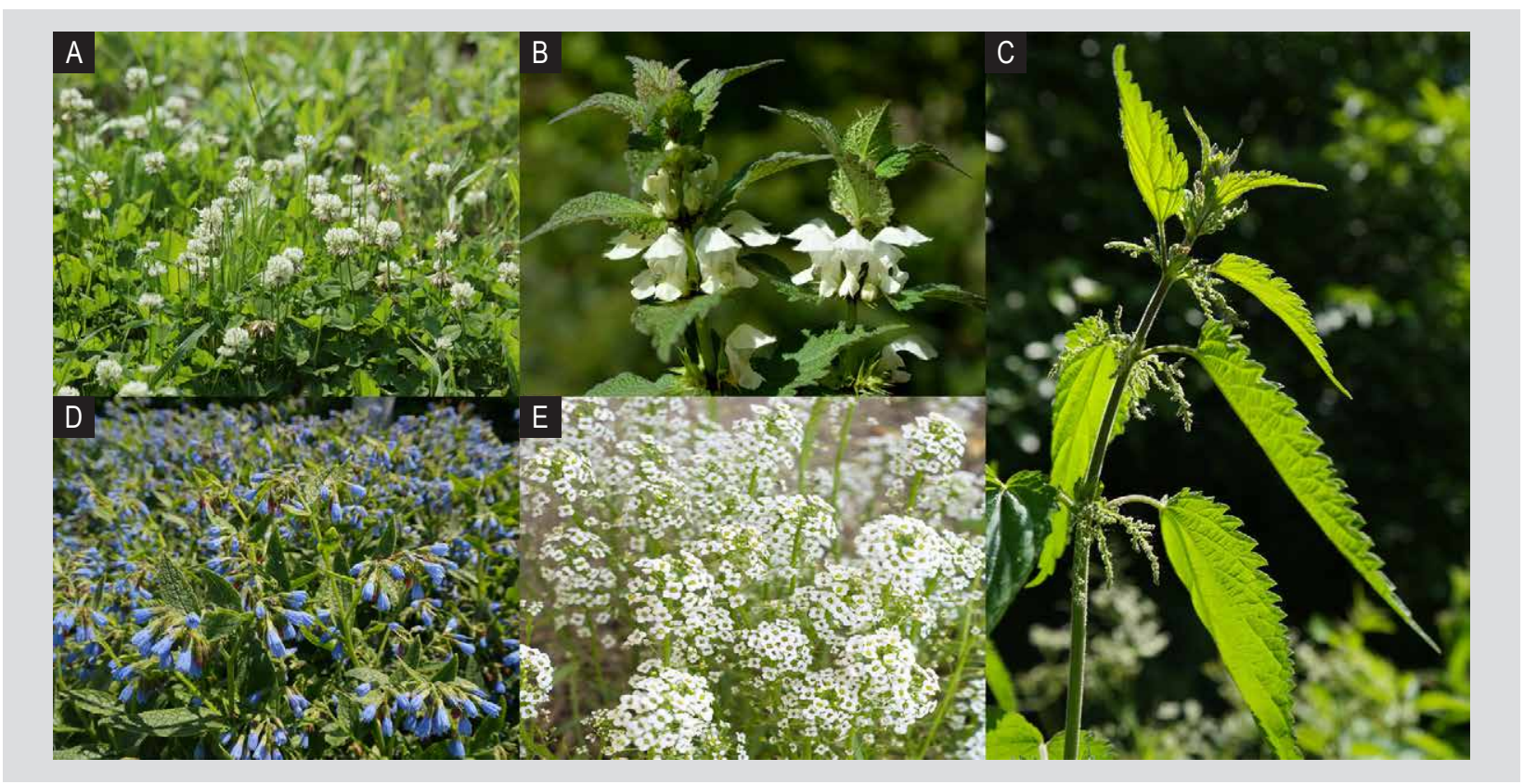

Figure 1. (A) flowering white clover (photo: zoosnow), (B) white nettle (photo: Frauke Riether), (C) common nettle (photo: Hans Braxmeier), (D) rough comfrey (photo: Hans Braxmeier), and (E) common gypsophila (photo: Stephanie Pratt). All pictures were acquired from https://pixabay.com under free Pixabay Licence.

used was a store-bought organically grown common nettle powder (Superfruit Scandinavia AB, Stockholm, Sweden). Each treatment was represented by six replicates, and each replicate included 60 nymphs. Preliminary tests and previous studies (Vaga et al., 2020) show that the crickets mature between 54-60 days. The experiment was therefore run for 62 days, at which time the first crickets on control feed had matured. At the end of the 62 days all remaining crickets were collected and frozen for further analysis.

The cricket nymphs were housed in transparent plastic boxes (W21 × D17 $\times \mathrm{H} 15 \mathrm{~cm}$ ), with a stainless-steel meshcovered ventilation hole $(10 \times 4 \mathrm{~cm})$ on the side. The boxes were equipped with housing units made of black PEM pipes (ø $25 \mathrm{~mm}$ ) (Vaga et al., 2018), to increase the surface area and provide hiding places for the crickets. Water was provided in $10 \mathrm{~cm}$ long plastic vials $(\varnothing 14 \mathrm{~mm})$ with cotton plugs. Feed was provided on plastic petri dishes. Water vials were changed every 15 days (before they were empty) and feed every 5 or 10 days. New feed was added to the cages continuously to ensure ad libitum feeding. Sodium is an essential nutrient for all living organisms but solely forage based diets are low in sodium (Berger and Cunha, 1993). Availability of lick salt for plant-based diets improves growth performance of house crickets (Vaga et al., unpublished) and therefore Himalayan mineral lick salt (Albert Kerbl GmbH, Buchbach, Germany) was freely available in all cricket boxes. The boxes were kept on two shelves, with half the replicates on the lower and half on the higher shelf. The temperature difference between shelves was around $0.7^{\circ} \mathrm{C}$. Box location was considered in the statistical analysis.
Weight of crickets and feed refusals were weighed every seven days. During weighing, other items (feeder, water tube, feed and frass) were removed and the crickets were weighed within the box. Feed was weighed separately within the feeder and thereafter old feed (feed refusals) was removed and new feed added, weighed and placed back in the box. All weighing (feed, cricket boxes, etc.) was performed on the

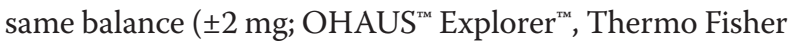
Scientific Inc., Gothenburg, Sweden). Cricket survival was determined by taking a picture of the crickets in the box (after removal of feeder, water tube, feed and frass) every seven days, prior to weighing and visually counting the individuals.

\section{Design and management of experiment 2}

Experiment 2 was designed to test to what extent house crickets consume forages when other protein-rich (rapeseed meal) and starch-rich (wheat flour) feeds are freely available, and the effect of such supplementation on house cricket growth and survival. The experimental set-up consisted of control feed and three dietary treatments where crickets had ad libitum access to rapeseed meal (ExPro 00SF), wheat meal and one of three options: early-cut red clover hay, latecut red clover hay or white nettle hay. Crickets on the same diet were housed in the same box (W27 × D39 × H29 cm), with access to housing, water and salt as described for experiment 1 . At least $100 \mathrm{mg}$ of nymphs were started on the control diet, while a greater amount $(\sim 500 \mathrm{mg})$ of nymphs were started on the other diets. The experiment was run for 62 days, to assure that some crickets on control 
feed matured and thereafter all crickets remaining in the boxes were collected and frozen $\left(-20^{\circ} \mathrm{C}\right)$ for further analysis. All crickets on the control diet $(n=104)$ were weighed individually and assessed for sex and developmental stage (adult male, adult female or nymph). The sex of nymphs was considered unknown in the analysis. For the other dietary treatments, a representative sample was collected from the whole group and $\geq 70$ crickets were individually weighed and assessed for sex and developmental stage. To check the representativeness of the individual weights, all remaining crickets were also counted and weighed as a group. Some crickets lost a leg during collection, which was taken account in the statistical analysis of weight. Feed offered and feed leftovers were weighed.

\section{Chemical analysis}

Dry matter (DM) concentration was determined in feeds before the start of the experiment and in feed refusals. Feed DM concentration was determined by drying at $105^{\circ} \mathrm{C}$ for 16 hours and ash concentration by incineration at $500^{\circ} \mathrm{C}$ for 4 hours (AOAC, 1990). All feeds were analysed for crude protein (CP) and soluble CP (Nordic Committee of Food Analysis, 1979) using a 2020 Digestor and a 2400 Kjeltec Analyser Unit (FOSS Analytical A/S, Hilleröd, Denmark). Neutral detergent fibre and acid detergent fibre were analysed with heat-stable $\alpha$-amylase and sodium sulphite (Mertens et al., 2002) using the filter bag technique in an ANKOM200 Fiber Analyzer (Ankom Technology Corp., Macedon, NY, USA). Starch was analysed according to Larsson and Bengtsson (1983) and ether extract according to Method B in the Official Journal of the European Communities (1984). Total trace mineral levels in feeds was determined by Spectro Blue ICP (SPECTRO Analytical Instruments $\mathrm{GmbH}$, Kleve, Germany) according to modified method SS-EN ISO 11885/SS 028311 (SIS, 1997). In analysis of ether extract, starch, soluble CP and mineral concentrations in feeds after the feeding trial (experiment 1 ), it was deemed unnecessary to include rough comfrey, common nettle and common gypsophila in the analysis due to the unacceptably poor performance of these feeds in the experiment.

\section{Calculations and statistical analysis}

Feed consumption was calculated every seven days as the difference between amount of feed supplied and refusals. The DM content of feed and refusals was analysed at the beginning and end of the experiment. FCR was calculated as $\mathrm{g}$ feed DM consumed per $\mathrm{g}$ weight gain. Total mean feed DM consumption was divided by mean cricket weight at day 62. Diet effect on cricket weight and feed intake was analysed by ANOVA, using the 'lmer' function from the $\mathrm{R}$ package 'Ime4' in R software (version 3.6.3; R Core Team, 2020) using the model:
$Y_{i j k}=\mu+F_{i}+s_{j}+d_{k}+e_{i j k}$

where $Y_{i j k}$ is a dependent variable and $\mu$ is the overall mean of observations, $F_{i}$ is the effect of diet, $s_{j}$ is the random effect of box location on the shelf (lower or upper shelf), $d_{k}$ is the random effect of sampling day and $e_{\mathrm{ijk}}$ is the random residual error. The model was corrected for multiple comparisons by Tukey-Kramer adjustment. Conditional and marginal coefficient of determination for generalised mixed-effect models were calculated using the $\mathrm{R}$ function 'r.squaredGLMM' from the R package 'MuMIn'. Cricket survival was analysed by Cox's proportional hazards mixed effects model (Cox, 1972; Therneau and Grambsch, 2000) using the 'coxme' function from the R package 'coxme' (Therneau, 2018). Data was visualised using Kaplan-Meier curve produced using 'survfit' function in R package 'survival'. The analysis is described in more detail by Quek et al. (2020).

Weight data from experiment 2 were analysed by ANOVA using the GLM procedure in SAS (version 9.4; SAS Institute Inc., Cary, NC, USA) using the model:

$Y_{i j k}=\mu+D_{i}+E_{j}+F_{k}+e_{i j k}$

where $D_{i}$ is the effect of diet, $E_{j}$ is the effect of sex (unknown, male or female), $F_{k}$ is the effect of leg missing (yes or no) and $\mathrm{e}_{\mathrm{ijk}}$ is the random residual error. Differences were declared statistically significant at $P \leq 0.05$. For comparisons of proportions of non-matured individuals and matured males and females between treatments, Chi-square analysis was used. If a class had zero observations, one observation was added.

\section{Results}

\section{Feed composition}

The CP content of feeds ranged from 116 to $222 \mathrm{~g} / \mathrm{kg}$ DM, being highest in white clover and lowest in common gypsophila (Table 2). The control diet was high in starch, whereas the starch concentration in white nettle and white clover was less than $20 \mathrm{~g} / \mathrm{kg}$ DM. Ether extract content was low in the control feed, white clover and white nettle. Both white nettle and white clover had higher macro-mineral and lower micro-mineral concentration than the control diet (Table 3).

\section{Cricket survival and forage acceptance in experiment 1}

Crickets fed white clover and white nettle diets accepted the feed and showed growth during the trial period (Figure 2). Diets consisting of rough comfrey, common nettle and common gypsophila were not accepted, and mortality in the first seven days was on average $79 \%(\mathrm{SD}=6.7)$, so the parts of the trial with these three plants were terminated 
Table 2. Chemical composition of control feed and experimental feeds. ${ }^{1}$

\begin{tabular}{|c|c|c|c|c|c|c|c|}
\hline \multirow[t]{2}{*}{ Feed } & \multirow[t]{2}{*}{$\mathrm{DM}(\mathrm{g} / \mathrm{kg})$} & \multicolumn{5}{|c|}{ g/kg DM } & \multirow[t]{2}{*}{$\mathrm{sCP}(\mathrm{g} / \mathrm{kg} \mathrm{CP})$} \\
\hline & & $\mathrm{CP}$ & NDF & EE & Starch & Ash & \\
\hline Control feed & 929 & 189 & 180 & 25 & 376 & 59 & 231 \\
\hline White nettle & 944 & 164 & 240 & 32 & 21 & 126 & 260 \\
\hline White clover & 937 & 222 & 270 & 20 & 13 & 92 & 394 \\
\hline Rough comfrey & 937 & 181 & 267 & NA & NA & 178 & 425 \\
\hline Common nettle & 938 & 142 & 395 & NA & NA & 159 & 212 \\
\hline Common gypsophila & 946 & 116 & 498 & NA & NA & 87 & 663 \\
\hline Early-cut red clover & 939 & 199 & 332 & NA & 19 & 123 & 569 \\
\hline Late-cut red clover & 946 & 130 & 489 & NA & 22 & 88 & 338 \\
\hline
\end{tabular}

${ }^{1} \mathrm{DM}=$ dry matter; $\mathrm{CP}=$ crude protein; $\mathrm{NDF}=$ neutral detergent fibre; $\mathrm{EE}$ = ether extract; $\mathrm{SCP}=$ soluble $\mathrm{CP} ; \mathrm{NA}=$ not analysed.

Table 3. Micro- and macro-mineral concentrations in control feed and experimental feeds.

\begin{tabular}{|c|c|c|c|c|c|c|c|c|c|c|}
\hline \multirow[t]{2}{*}{ Feed } & \multicolumn{6}{|c|}{ g/kg dry matter } & \multicolumn{4}{|c|}{$\mathrm{mg} / \mathrm{kg}$ dry matter } \\
\hline & $\mathbf{N}$ & $\mathrm{Ca}$ & K & $\mathrm{Mg}$ & $\mathbf{P}$ & $\mathrm{S}$ & $\mathrm{Cu}$ & $\mathrm{Fe}$ & $\mathrm{Mn}$ & $\mathrm{Zn}$ \\
\hline Control & 29.9 & 10.1 & 9.3 & 3.8 & 7.2 & 2.7 & 14.1 & 205 & 193 & 142 \\
\hline White nettle & 30.8 & 7.6 & 52.7 & 3.9 & 5.3 & 2.0 & 8.7 & 141 & 50 & 32 \\
\hline White clover & 34.5 & 10.8 & 35.3 & 2.4 & 3.5 & 1.9 & 8.5 & 119 & 37 & 30 \\
\hline Early-cut red clover & 34.2 & 18.6 & 37.5 & 2.9 & 2.9 & 2.2 & 14.8 & 219 & 33 & 26 \\
\hline Late-cut red clover & 22.4 & 11.9 & 28.8 & 2.3 & 1.8 & 1.4 & 12.9 & 80 & 21 & 21 \\
\hline
\end{tabular}

after 14 days. The survival rate on the white nettle diet was no different from the control diet for the first 28 days (approximated hazard ratio $=0.928, P=0.188$ ), but declined quickly thereafter. The mortality of crickets on the white clover diet was high $(78 \%, \mathrm{SD}=4.3)$ in the first 21 days, but only marginally lower than for crickets on the white nettle for the rest of the experiment (approximated hazard ratio $0.81, P=0.141$; Figure 3 ). The survival of crickets reared on the white clover diet and white nettle diet was lower $(P<0.001)$ than the crickets on control feed (approximated hazard ratios 3.43 and 1.58 , respectively).

\section{Growth, weight and feed intake in experiment 1}

Crickets on control diet grew to a mean weight of $201 \pm 14$ mg by day 62 . In this group, 11 crickets reached adulthood (9 females, 2 males). The mean cricket weight for the white nettle diet $(2.2-9.0 \mathrm{mg})$ was higher $(P=0.033)$ than for the white clover diet (1.9-5.5 mg) during the first 21 days, but the final average weight of crickets on both diets was $32 \pm 5$ mg on day 62 (Figure 2). The mean weight of crickets on the white nettle and control diet did not differ significantly during the first 28 days, by which time the mean weight of crickets was 15 and $19 \mathrm{mg}(\mathrm{SEM}=2.1)$, respectively.
Weight gain of crickets fed the white nettle diet became significantly $(P<0.011)$ lower than crickets on the control diet from day 35 .

Daily feed DM intake of crickets (mg/cricket/day) during the first 21 days was not significantly different between the white clover, white nettle and control diets (Figure 4; conditional R2 =0.938, marginal R2 =0.927). After 62 days, total DM consumption (mg/cricket) was not different between crickets fed the white nettle and white clover diets, $128 \pm 13$ and $127 \pm 30 \mathrm{mg}$, respectively, but in both cases intake was significantly lower than in the control group ( $417 \pm 79 \mathrm{mg} ; P<0.001)$. Total weight of all crickets ( $\mathrm{n}=6$ samples) by day 62 was $29.1 \mathrm{~g}$ in the control, $0.475 \mathrm{~g}$ in the white clover group and $1.918 \mathrm{~g}$ in the white nettle group. Feed conversion ratio (g DM consumed/g cricket weight; FCR) in the control group was 2.07.

\section{Cricket feed choices, weight and development in experiment 2}

The proportional of cricket feed intake of the different feeds is shown in Table 4. Red clover was consumed, while white nettle was not. The proportion of wheat meal consumption 


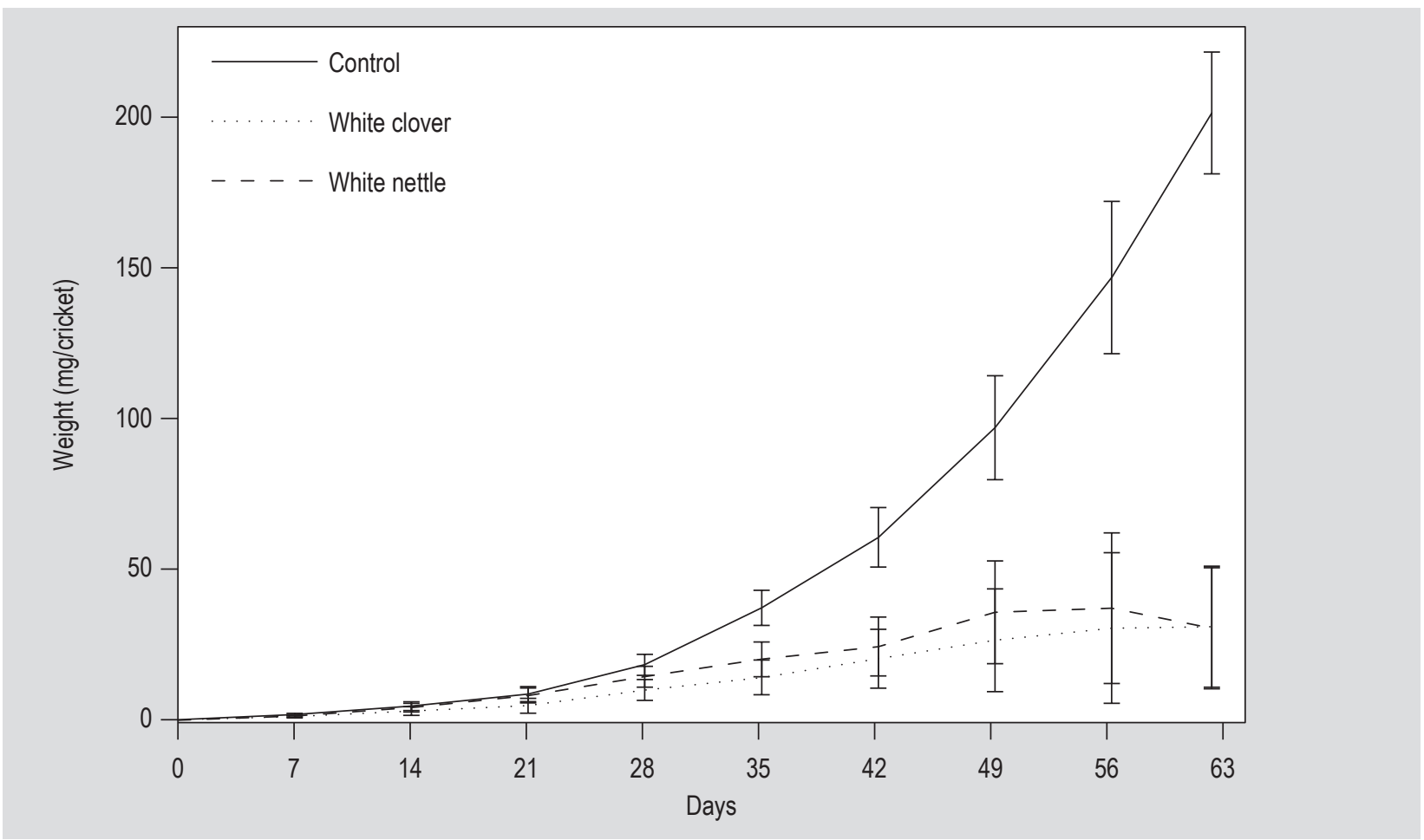

Figure 2. Weight (mg) of crickets fed a control diet, white nettle and white clover for 62 days (conditional R2 = 0.934, marginal R2 $=0.926$ ). Each point represents mean of six samples and bars represents the $95 \%$ confidence intervals.

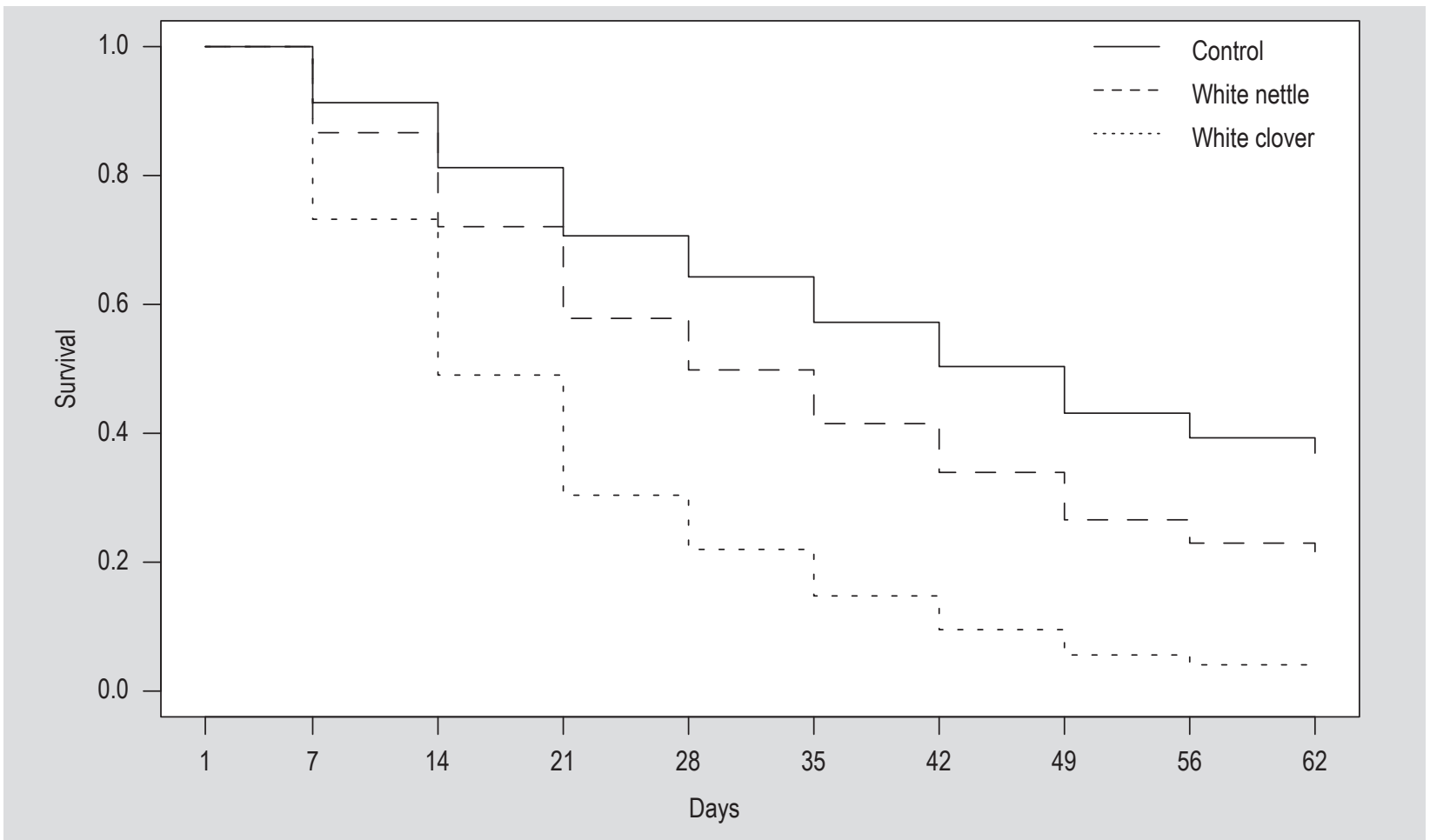

Figure 3. The Kaplan-Meier curve from the Cox proportional hazards mixed-effects model for crickets reared on control feed (solid line), white nettle (dashed line) and white clover (dotted line). 


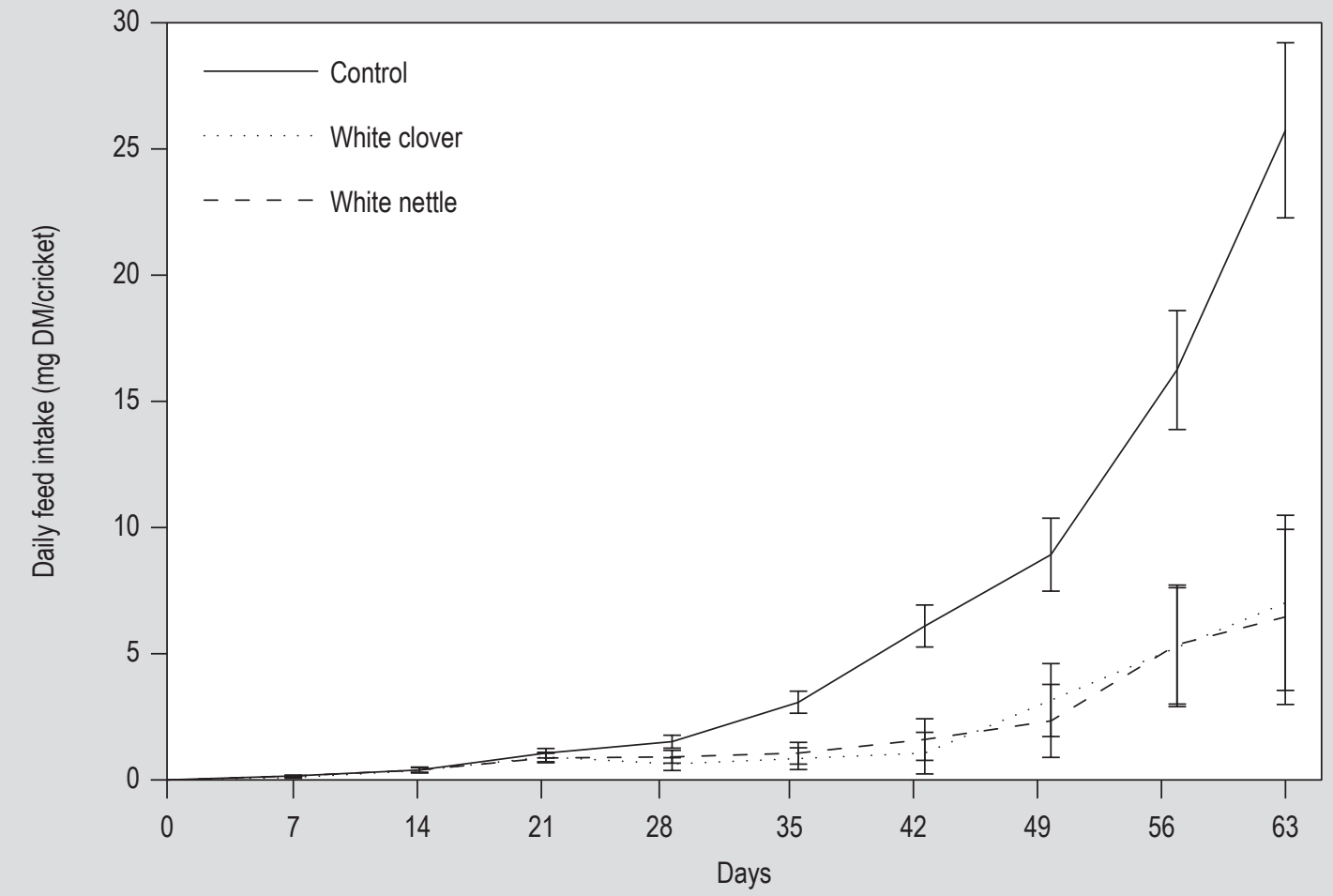

Figure 4. Feed dry matter (DM) intake in crickets fed a control diet, white nettle and white clover for 62 days. Each point represents mean of six samples $\pm \mathrm{SE}$.

did not differ between treatments. There was an effect of sex, development stage and diet on cricket weight $(P<0.001)$. The weight of crickets offered white nettle $(151 \pm 10 \mathrm{mg} /$ cricket) was lower $(P<0.001)$ than that of crickets offered the control feed $(242 \pm 11 \mathrm{mg} /$ cricket). However, there was no difference $(P=0.95)$ between the weight of crickets fed the control diet and crickets offered the clover diets (early-cut red clover $221 \pm 10 \mathrm{mg} /$ cricket, late-cut red clover $263 \pm 13$ $\mathrm{mg} /$ cricket). Compared with the control diet, the proportion of females and males that reached maturity was higher in the early-cut and late-cut red clover groups, and lower in the white nettle group (Table 5).

\section{Discussion}

This study evaluates the potential for using European flowering plants (angiosperms; Figure 1) as feed for reared house crickets. The plants evaluated were chosen because they have good potential to support wild biodiversity. White clover and white nettle showed promise as cricket feeds, either as part of a mixed diet or as sole feed. Growth performance and survival rate in crickets fed white nettle were similar to those in crickets fed a control feed for the first 21-28 days of life (Figures 2 and 3). Feed based on white nettle could therefore be an option for smallholder cricket farmers and reduce the need for expensive complex feeds during the first half of the cricket development period. However, for white clover the survival rate was low in early stages of development, making it unsuitable as sole feed
Table 4. Proportion (\%) of feed intake by crickets offered a choice of rapeseed meal, wheat meal and one of three dietary treatments (early-cut or late-cut red clover or white nettle) ad libitum for 62 days.

$\begin{array}{llll} & \text { Rapeseed } & \text { Wheat meal } & \text { Treatment } \\ \text { Early-cut red clover } & 39 & 31 & 30 \\ \text { Late-cut red clover } & 53 & 32 & 15 \\ \text { White nettle } & 64 & 37 & 0\end{array}$

Table 5. Proportion (\%) of individuals that did not mature, matured females and males in the groups of crickets offered a control feed or an experimental diet containing rapeseed meal, wheat meal and either early-cut or late-cut red clover or white nettle ad libitum for 62 days. $P$-values indicate differences from the control feed.

$\begin{array}{llccc} & \begin{array}{l}\text { Not } \\ \text { matured }\end{array} & \begin{array}{l}\text { Matured } \\ \text { females }\end{array} & \begin{array}{l}\text { Matured } \\ \text { males }\end{array} & P \text {-value } \\ \text { Control } & 95 & 5 & 0 & \\ \text { Early-cut red clover } & 75 & 17 & 8 & <0.001 \\ \text { Late-cut red clover } & 69 & 21 & 10 & <0.001 \\ \text { White nettle } & 99 & 1 & 0 & 0.128\end{array}$


for house crickets. Mortality of crickets fed rough comfrey, common nettle and common gypsophila was very low, therefore these plants cannot be recommended as feed for house crickets.

While often used in folk medicine, the nutritional profile of white nettle as an animal feed has not been studied previously. This study showed that the CP, starch and mineral (Ca, Mn, and $\mathrm{Zn}$ ) concentrations in white nettle were lower than in the cereal- and rapeseed-based control feed. These nutrients are regularly mentioned as being important for house cricket growth and/or survival (Cortes Ortiz et al., 2016). Despite the lower concentrations of key nutrients, the house crickets on the pure white nettle diet grew equally well for the first 21 days as those on the control diet (Figure 2). This is may be due to that the CP concentration in white nettle is well above the minimum threshold of 10\% of DM (McFarlane, 1964). However, the mortality of crickets was high on white nettle diet despite the relatively high CP content (22\%). It was not possible to identify if there was a limitation of nutrients and how it affected cricket growth and mortality in this study. In spite of this, our findings add to the growing evidence that the performance of house crickets in rearing conditions cannot only be explained by the concentration of CP, lipids or carbohydrate in the diet (Miech et al., 2016; Oonincx et al., 2015; Orinda et al., 2017). Further detailed analyses are needed to develop suitable feed for this species.

The good growth and survival performance of crickets in the early stages of life observed for the pure white nettle diet could have been influenced by available nutrients from eggshells, unhatched eggs and cannibalism. However, since cricket nymphs were removed from the incubation medium shortly after hatching, the availability of leftover nutrients from eggs would have been negligible. The higher survival rate of crickets on white nettle compared with white clover during the early days could possibly be related to the high nectar content of white nettle flowers. Both plants were collected during blooming, but the amount of nectar per flower in white nettle $(2.9 \mathrm{mg})$ is much higher than in white clover (0.01 mg) (Becher et al., 2016; Sulborska et al., 2014), therefore this plant had the potential to initially provide more readily available energy for cricket nymphs.

Luckey and Stone (1968) attributed lower growth performance of house crickets fed pure grass to low salt content in the grass, and found that addition of sodium to grass diets improved house cricket growth by two-fold and increased nymph survival from 84 to $92 \%$. As mineral salt was made available to all crickets ad libitum in this study sodium should not have been a limiting factor for crickets fed any of the diets. Two main limiting factors contributing to low growth performance of the house crickets might be the low fat (ether extract) and starch content in most forages (Orinda et al. 2017). El-Damanhouri (2011) found that young female two-spotted crickets (Gryllus bimaculatus) developed best on diets with $5 \%$ crude fat and $38 \% \mathrm{~N}$-free extract, compared with diets with either reduced fat (2\%) or reduced starch $(23 \% \mathrm{~N}$-free extract). This agrees well with the findings in the present study, where rapeseedand starch-rich wheat meal diets combined with forages improved growth and survival rates. The low fat content in our control diet (Table 3) may also explain the lower survival rate ( $<50 \%$ in experiment 1$)$ and longer development time ( $>56$ days to adulthood) obtained for the control group compared with previous studies. In some recent studies, the survival rate and development time of house crickets reared at temperatures $28-30{ }^{\circ} \mathrm{C}$ and fed chicken feed were reported to range between $55-80 \%$ and $37-48$ days, respectively (Oonincx et al., 2015; Sorjonen et al., 2019; Veenenbos and Oonincx, 2017).

Performance on the control feed was evaluated based on FCR and cricket weight. The average weight of house crickets reared on chicken feed or dog food is reported almost twice as high as on our control feed, 407-430 vs 201 mg (Nakagi and DeFoliart, 1991; Sorjonen et al., 2019; Tyree et al., 1976). However, the number of adults or maturity rate in relation to feed is seldom reported. A FCR of 2.07 on our control feed was about 2 -folds greater $(\mathrm{FCR}=0.94)$ than reported by Nakagi and DeFoliart (1991), but the crickets in that study were not reared from hatching, and was also reared for a much shorter time (24 days). Compared to FCR's of other livestock such as salmon, poultry and pigs, or T. testaceus fed on chicken feed (FCR 1.3, 1.8, 3.0 and 2.25, respectively) (Miech et al., 2016; Smil, 2002; Tacon and Metian, 2008) the performance of our control feed was comparatively good. A FCR below 2.0 would have been achieved also in our study if the harvest were done a few days earlier when the crickets had just matured.

A mixed diet is often used as control feed in research and in commercial rearing of house crickets (Gahukar, 2016). Successful rearing of Cambodian field crickets (T. testaceus) on wild plants or food by-products like cassava top- or Cleome rutidosperma-only diets has been reported by Miech et al. (2016). Our study is the first to compare feed based on wild flowering plants in Europe. Caution is needed when comparing diet effects on different cricket species. In studies feeding the same diets to house crickets and two-spotted crickets, Orinda et al. (2017) and Sorjonen et al. (2019) reported different effects of the feeds on survival and growth rate of these two species. To our knowledge, so far no single-plant feeds have been identified as suitable for house crickets. It is possible that a combination of two or more plants is needed to create feed that is suitable. In the present study, the survival rate of crickets fed white nettle was high during the first 21 days, whereas white clover promoted higher survival rate later in the growth period (21-42 days). This indicates that these two forages could be combined to improve house cricket survival compared 
to them as separate feeds. Previous studies support the use of mixed plant-based diets. Caparros Megido et al. (2016) showed that $20 \%$ inclusion of brown rice flour with cassava leaf flour and taro flower improved final weight and survival rate in house crickets. Further improvements were achieved by inclusion of a third ingredient (banana). Tyree et al. (1976) added a synthetic concentrate in increments to lucerne and timothy diets and reported that just $10 \%$ inclusion increased house cricket growth and survival to same level as in crickets fed the control diet (dog food). A diet consisting of chicken feed together with grasses or other low-cost plants would reduce feed costs (Gahukar, 2016; Hanboonsong et al., 2013), especially important for insect rearing in developing countries. If flowering plants could be used, this has the potential to greatly increase the sustainability of the rearing system.

Clover-based diets for house crickets are of interest due to the wide use of clovers in agriculture, clover's benefits for soil fertility (McKenna et al., 2018; Taylor and Quesenberry, 2013) and their potential as a food resource for bees and other pollinators (Dupont et al., 2011). In a previous study, we found that house cricket performance was low on red clover-only diets, but that red clover had potential as part of a mixed diet (Vaga et al., 2020). In experiment 1, crickets on the white nettle diet outperformed crickets fed white clover and the results were more similar to those reported for red clover (Vaga et al., 2020). Despite the relatively good performance of crickets on the white nettle-only diet, crickets did not consume any white nettle when rapeseed meal and wheat flour were available (Table 4). Red clover diets were consumed to some extent and availability of both early- and late-cut red clover hay increased the proportion of matured crickets compared with the control diet (Table 5). Crickets consumed about $15-30 \%$ of red clover, which indicates that at least one-third of the house cricket diet can be replaced with red clover without production losses if the other part of the diet is a concentrate. The optimal forage to concentrate ratio would likely depend on the type of concentrate and forage available, but Tyree et al. (1976) found that 10-90\% lucerne or timothy concentration in a diet resulted in no differences in house cricket survival and weight gain compared with a $100 \%$ concentrate and control diet. Regardless of forage inclusion, wheat flour (starch-rich) consumption remained between 31-37\% of all feeds in experiment 2 (Table 4). This gives an indication of the starch requirement in mixed diet formulation for house crickets.

The greater preference of crickets for early-cut red clover compared with late-cut (Table 4) may indicate a preference for higher crude protein concentration (early-cut clover) or a dislike of higher fibre content (late-cut clover) (Table 2). However, the effect of fibre content on performance of house crickets is not clearly understood. In some previous studies, higher fibre content has been associated with higher survival and growth rates of house crickets (Tyree et al. 1976; Veenenbos and Oonincx, 2017). In other studies, high fibre content has been used to explain lower growth rates (Nakagi and DeFoliart, 1991; Orinda et al., 2017). Interestingly in those studies, it can be noted that positive associations with growth and fibre content were seen for forages with crude fibre concentrations below $10 \%$ of DM and negative associations with crude fibre concentrations above $20 \%$ of DM. House crickets are omnivorous insects and at least some roughage content in the diet is considered beneficial for maximal growth and feed efficiency (Neville and Luckey, 1962). In Luckey and Stone (1968), Tyree et al. (1976) and the present study, inclusion of red clover, grasses or lucerne in a mixed diet significantly increased the survival and maturation rate of nymphs. Luckey and Stone (1968) fed house crickets synthetic concentrate diet mixed 1:1 with grass in a 30 day experiment and observed an increase in survival rate from 63 to $97 \%$ and in cricket weight from 8 to $138 \mathrm{mg}$ compared with concentrate feed alone. Tyree et al. (1976) found that diets including different ratios of timothy hay improved the survival rate of house crickets to $>90 \%$, compared with $82 \%$ on the control diet, and diets with lucerne inclusion gave an average of 8 crickets maturing in 28 days compared with one maturing on the control diet. Maturation means the end of growth in house crickets (except ovarian growth in females) and marks the optimum time for harvesting. Shorter growing time would allow the number of production cycles per year to be increased, and therefore a reduction in energy and feed costs.

House cricket production for food is on the rise. The ability of crickets to consume and grow on a variety of feeds, food by-products (Oonincx et al., 2015; Orinda et al., 2017; Sorjonen et al., 2019) and flowering plants is one of their main beneficial aspects from a sustainability point of view (Berggren et al., 2019). In this study, we did not identify a single forage species on which house crickets could thrive, but we found that house cricket production can benefit from forage-based mixed diets. The full benefits of rearing house crickets on forages and concentrate or by-productbased diets merits further research.

\section{Conclusions}

Five species of European flowering plants were evaluated as the sole feedstuff for reared house crickets. White nettle and white clover showed some potential as sole feedstuffs at the early and later development stage, respectively. Overall, the results indicated possible benefits from feeding a mixture of forage plants with complementary effects. With ad libitum feeding of protein-rich rapeseed meal, starch-rich wheat flour and a choice of white nettle or early-cut or late-cut red clover, house crickets consumed up to $30 \%$ of forages, but with a preference for early-cut red clover. Inclusion of red clover in the diet improved cricket maturation rate, without 
a reduction in growth. Likely benefits of forage-based mixed diets merit further research in feed development for house crickets.

\section{Acknowledgements}

We are grateful to Matthew Low for advice on statistical analyses. This project was funded by the Swedish research council Formas (no. 2016-00361).

\section{Conflict of interest}

The authors declare no conflict of interest.

\section{References}

Association of Official Analytical Chemists (AOAC), 1990. Official methods of analysis ( $15^{\text {th }} \mathrm{Ed}$.). AOAC, Arlington, VA, USA.

Becher, M.A., Grimm, V., Knapp, J., Horn, J., Twiston-Davies, G. and Osborne, J.L., 2016. BEESCOUT: a model of bee scouting behaviour and a software tool for characterizing nectar/pollen landscapes for BEEHAVE. Ecological Modelling 340: 126-133. https://doi. org/10.1016/j.ecolmodel.2016.09.013

Berger, L.L. and Cunha, T.J., 1993. Salt and trace minerals for livestock, poultry and other animals. Salt Institute, Alexandria, VA, USA.

Berggren, Å., Jansson, A. and Low, M., 2019. Approaching ecological sustainability in the emerging insects-as-food industry. Trends in Ecology and Evolution 34: 132-138. https://doi.org/10.1016/j. tree.2018.11.005

Bommarco, R., Lundin, O., Smith, H.G. and Rundlöf, M., 2012. Drastic historic shifts in bumble-bee community composition in Sweden. Proceedings of the Royal Society B: Biological Sciences 279: 309315. https://doi.org/10.1098/rspb.2011.0647

Booth, D.T. and Kiddell, K., 2007. Temperature and the energetics of development in the house cricket (Acheta domesticus). Journal of Insect Physiology 53(9): 950-953. https://doi.org/10.1016/j. jinsphys.2007.03.009

Caparros Megido, R., Alabi, T., Nieus, C., Blecker, C., Danthine, S., Bogaert, J., Haubruge, É. and Francis, F., 2016. Optimisation of a cheap and residential small-scale production of edible crickets with local by-products as an alternative protein-rich human food source in Ratanakiri Province, Cambodia. Journal of the Science of Food and Agriculture 96: 627-632. https://doi.org/10.1002/jsfa.7133

Collavo, A., Glew, R.H., Huang, Y.S., Chuang, L.T., Bosse, R. and Paoletti, M.G., 2005. House cricket small-scale farming. In: Paoletti, M.G. (ed.) Ecological implications of minilivestock: potential of insects, rodents, frogs and snails. CRC Press, Boca Raton, FL, USA, pp. 519-544.

Cortes Ortiz, J.C., Ruiz, A.T., Morales-Ramos, J.A., Thomas, M., Rojas, M.G., Tomberlin, J.K., Yi, L., Han, R., Giroud, L. and Jullien, R.L., 2016. Insect mass production technologies. In: Dossey, A.T., Morales-Ramos, J.A. and Rojas, M.G. (eds.) Insects as sustainable food ingredients. Academic Press, San Diego, CA, USA, pp. 153-201. https://doi.org/10.1016/B978-0-12-802856-8.00006-5

Cox, D.R., 1972. Regression models and life-tables. Journal of the Royal Statistical Society: Series B (Methodological) 34: 187-202.
Darwent, A.L. and Coupland, R.T., 1966. Life history of Gypsophila paniculata. Weeds 14: 313-318. https://doi.org/10.2307/4040974.

Dupont, Y.L., Damgaard, C. and Simonsen, V., 2011. Quantitative historical change in bumblebee (Bombus spp.) assemblages of red clover fields. PLoS ONE 6: e25172. https://doi.org/10.1371/ journal.pone.0025172

El-Damanhouri, H.I.H., 2011. Studies on the influence of different diets and rearing conditions on the development and growth of the two-spotted cricket Gryllus bimaculatus De Geer. PhD thesis, University of Bayreuth, Bayreuth, Germany.

Emery, S.M. and Doran, P.J., 2013. Presence and management of the invasive plant Gypsophila paniculata (baby's breath) on sand dunes alters arthropod abundance and community structure. Biological Conservation 161: 174-181. https://doi.org/10.1016/j. biocon.2013.03.015

European Communities, 1984. Determination of crude oils and fat. Method B. Official Journal of the European Communities 15: 29-30.

Gahukar, R.T., 2016. Edible insects farming: efficiency and impact on family livelihood, food security, and environment compared with livestock and crops. In: Dossey, A.T., Morales-Ramos, J.A. and Rojas, M.G. (eds.) Insects as sustainable food ingredients. Academic Press, San Diego, CA, USA, pp. 85-111. https://doi.org/10.1016/ B978-0-12-802856-8.00004-1

Ghouri, A.S.K. and McFarlane, J.E., 1958. Observations on the development of crickets. The Canadian Entomologist 90: 158-165. https://doi.org/10.4039/Ent90158-3

Hanboonsong, Y., Jamjanya, T. and Durst, P.B., 2013. Six-legged livestock: edible insect farming, collection and marketing in Thailand. Food and Agriculture Organization of the United Nations, RAP publication 2013/03, Bangkok, Thailand.

James, D.G., Lauby, G., Seymour, L. and Buckley, K., 2015. Beneficial insects associated with stinging nettle, Urtica dioica Linnaeus, in central Washington State. The Pan-Pacific Entomologist 91: 82-90. https://doi.org/10.3956/2014-91.1.082

Karlsson, J., Spörndly, R., Lindberg, M. and Holtenius, K., 2018. Replacing human-edible feed ingredients with by-products increases net food production efficiency in dairy cows. Journal of Dairy Science 101: 7146-7155. https://doi.org/10.3168/jds.2017-14209

Larsson, K. and Bengtsson, S., 1983. Metodbeskrivning Nr 22. Statens Iantbrukskemiska Iaboratorium, Uppsala, Sweden.

Luckey, T.D. and Stone, P.C., 1968. Cricket nutrition: supplementation of grass by known nutrients. Journal of Insect Physiology 14: 15331534. https://doi.org/10.1016/0022-1910(68)90087-5

Łuczaj, L., Pieroni, A., Tardío, J., Pardo-de-Santayana, M., Sõukand, R., Svanberg, I. and Kalle, R., 2012. Wild food plant use in $21^{\text {st }}$ century Europe: the disappearance of old traditions and the search for new cuisines involving wild edibles. Acta Societatis Botanicorum Poloniae 81: 359-370. https://doi.org/10.5586/asbp.2012.031

McFarlane, J.E., 1964. The protein requirements of the house cricket, Acheta domesticus L. Canadian Journal of Zoology 42: 645-647. https://doi.org/10.1139/z64-055

McKenna, P., Cannon, N., Conway, J. and Dooley, J., 2018. The use of red clover (Trifolium pratense) in soil fertility-building: a review. Field Crops Research 221: 38-49. https://doi.org/10.1016/j. fcr.2018.02.006 
Mertens, D.R., Allen, M., Carmany, J., Clegg, J., Davidowicz, A., Drouches, M., Frank, K., Gambin, D., Garkie, M., Gildemeister, B., Jeffress, D., Jeon, C.S., Jones, D., Kaplan, D., Kim, G.N., Kobata, S., Main, D., Moua, X., Paul, B., Robertson, J., Taysom, D., Thiex, N., Williams, J. and Wolf, M., 2002. Gravimetric determination of amylase-treated neutral detergent fiber in feeds with refluxing in beakers or crucibles: collaborative study. Journal of AOAC International 85: 1217-1240.

Miech, P., Berggren, Å., Lindberg, J.E., Chhay, T., Khieu, B. and Jansson, A., 2016. Growth and survival of reared Cambodian field crickets (Teleogryllus testaceus) fed weeds, agricultural and food industry by-products. Journal of Insects as Food and Feed 2: 285-292. https:// doi.org/10.3920/JIFF2016.0028

Mossberg, B., Stenberg L. and Ericson, S., 1992. Den Nordiska floran. Wahlström \& Widstrand, Stockholm, Sweden.

Nakagaki, B.J. and DeFoliart, G.R., 1991. Comparison of diets for massrearing Acheta domesticus (Orthoptera: Gryllidae) as a novelty food, and comparison of food conversion efficiency with values reported for livestock. Journal of Economic Entomology 84: 891-896. https:// doi.org/10.1093/jee/84.3.891

Neville, P.F. and Luckey, T.D., 1962. Carbohydrate and roughage requirement of the cricket, Acheta domesticus. The Journal of Nutrition 78: 139-146. https://doi.org/10.1093/jn/78.2.139

Nordic Committee on Food Analysis, 1979. Nitrogen. Determination in food and feed according to Kjeldahl. Report no. 6. Nordic Committee on Food Analysis, Uppsala, Sweden.

Oonincx, D.G.A.B., Van Broekhoven, S., Van Huis, A. and Van Loon, J.J.A., 2015. Feed conversion, survival and development, and composition of four insect species on diets composed of food by-products. PLoS ONE 14: e0222043. https://doi.org/10.1371/ journal.pone. 0144601

Orinda, M.A., Mosi, R.O., Ayieko, M.A. and Amimo, F.A., 2017. Growth performance of common house cricket (Acheta domesticus) and field cricket (Gryllus bimaculatus) crickets fed on agro-byproducts. Journal of Entomology and Zoology Studies 5: 1664-1668.

Pullin, A.S., 1987. Changes in leaf quality following clipping and regrowth of Urtica dioica, and consequences for a specialist insect herbivore, Aglais urticae. Oikos 49: 39-45. https://www.jstor.org/ stable/3565552

Quek, X.T., Liang, L., Tham, H.H., Yeo, H., Tan, M.K. and Tan, H.T.W., 2020. Are the growth and survival of Acheta domesticus comparable when reared on okara, waste vegetables and premium animal feed? Journal of Insects as Food and Feed 6: 161-168. https://doi. org/10.3920/JIFF2019.0039

R Core Team, 2020. R: a language and environment for statistical computing. R Foundation for Statistical Computing, Vienna, Austria. Available at: https://www.R-project.org/.

Reyneri, A., Grignani, C. and Cavallero, A., 1996. The role of white clover in the South European grazing systems: the Po plain situation. Reu Technical Series (FAO) 42: 19-27.

Rivin, J., Miller, Z. and Matel, O., 2012. Using food waste as livestock feed. University of Wisconsin Madison, WI, USA.

Semberg, E., De Miranda, J.R., Low, M., Jansson, A., Forsgren, E. and Berggren, Å., 2019. Diagnostic protocols for the detection of Acheta domesticus densovirus (AdDV) in cricket frass. Journal of Virological Methods 264: 61-64. https://doi.org/10.1016/j.jviromet.2018.12.003
Smil, V., 2002. Worldwide transformation of diets, burdens of meat production and opportunities for novel food proteins. Enzyme and Microbial Technology 30: 305-311. https://doi.org/10.1016/ S0141-0229(01)00504-X

Sorjonen, J.M., Valtonen, A., Hirvisalo, E., Karhapää, M., Lehtovaara, V.J., Lindgren, J., Marnila, P., Mooney, P., Mäki, M., Siljander-Rasi, H. and Tapio, M., 2019. The plant-based by-product diets for the mass-rearing of Acheta domesticus and Gryllus bimaculatus. PLoS ONE 14: e0218830. https://doi.org/10.1371/journal.pone.0218830 Straub, P., Tanga, C.M., Osuga, I., Windisch, W. and Subramanian, S., 2019. Experimental feeding studies with crickets and locusts on the use of feed mixtures composed of storable feed materials commonly used in livestock production. Animal Feed Science and Technology 255: 114215. https://doi.org/10.1016/j.anifeedsci.2019.114215

Sulborska, A., Dmitruk, M., Konarska, K. and Weryszko-Chmielewska, E., 2014. Adaptation of Lamium album L. flowers to pollination by Apoidea. Acta Scientiarum Polonorum. Hortorum Cultus 13: 31-43. Swedish Institute for Standards (SIS), 1997. Soil analysis Determination of trace elements in soils - Extraction with nitric acid (SS028311) [in Swedish]. SIS, Stockholm, Sweden.

Tacon, A.G.J. and Metian, M., 2008. Global overview on the use of fish meal and fish oil in industrially compounded aquafeeds: trends and future prospects. Aquaculture 285: 146-158. https:// doi.org/10.1016/j.aquaculture.2008.08.015

Taylor, N.L. and Quesenberry, K.H., 2013. Red clover science. Current plant science and biotechnology in agriculture. Vol. 28. Springer Science and Business Media, Berlin, Germany, pp. 44-79. https:// doi.org/10.1007/978-94-015-8692-4

Therneau, T.M., 2018. Coxme: mixed effects Cox models. R-package, version 2.2-3. Available at: http://cran.r-project.org/package=coxme.

Therneau, T.M. and Grambsch, P.M., 2000. Modeling survival data: extending the Cox model. Springer-Verlag, Berlin, Germany.

Turner, N.J., Łuczaj, Ł.J., Migliorini, P., Pieroni, A., Dreon, A.L., Sacchetti, L.E. and Paoletti, M.G., 2011. Edible and tended wild plants, traditional ecological knowledge and agroecology. Critical Reviews in Plant Sciences 30(1-2): 198-225. https://doi.org/10.10 80/07352689.2011.554492

Tyree, W.A., Pfander, W.H. and Stone, P.C., 1976. Response of crickets to amount of forage in the diet. Journal of Dairy Science 59: 164-166. https://doi.org/10.3168/jds.s0022-0302(76)84172-0

Vaga, M., Berggren, Å., Pauly, T. and Jansson, A., 2020. Effect of harvesting time and conservation strategy of red clover on growth performance of house crickets (Acheta domesticus). Journal of Insects as Food and Feed 6(2): 179-189. https://doi.org/10.3920/ JIFF2019.0038

Vaga, M., Gustafsson, E. and Jansson, A., 2018. Evaluation of reusable hiding units for rearing house crickets (Acheta domesticus). In: Book of Abstracts of the $6^{\text {th }}$ Annual Meeting of the European Federation of Animal Science, August 27-31, 2018, Dubrovnik, Croatia, pp. 470.

Veenenbos, M.E. and Oonincx, D.G.A.B., 2017. Carrot supplementation does not affect house cricket performance (Acheta domesticus). Journal of Insects as Food and Feed 3: 217-221. https://doi. org/10.3920/JIFF2017.0006

Wilkinson, J.M., 2011. Re-defining efficiency of feed use by livestock. Animal 5: 1014-1022. https://doi.org/10.1017/s175173111100005x 
